
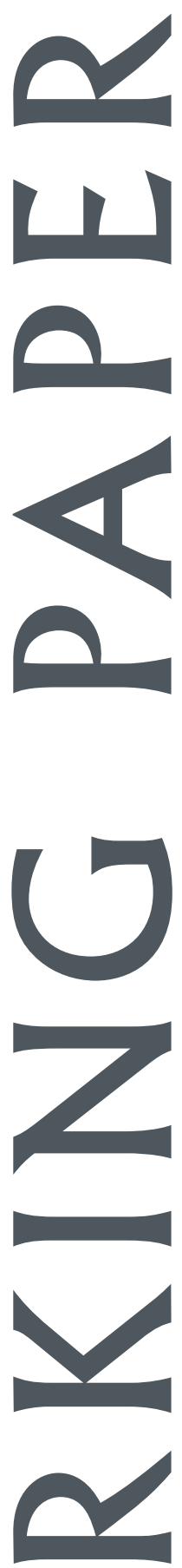

EAST-WEST CENTER 
The U.S. Congress established the East-West Center in 1960 to foster mutual understanding and cooperation among the governments and peoples of the Asia Pacific region including the United States. Funding for the Center comes from the U.S. government with additional support provided by private agencies, individuals, corporations, and Asian and Pacific governments.

East-West Center Working Papers are circulated for comment and to inform interested colleagues about work in progress at the Center.

For more information about the Center or to order publications, contact:

Publication Sales Office

East-West Center

1601 East-West Road

Honolulu, Hawaii 96848-1601

Telephone: 808-944-7145

Facsimile: 808-944-7376

Email: ewcbooks@EastWestCenter.org

Website: www.EastWestCenter.org 


\title{
Maternal Exposure to Biomass Smoke and Reduced Birth Weight in Zimbabwe
}

\author{
Vinod Mishra, Xiaolei Dai, Kirk R. Smith, \\ and Lasten Mika
}

Vinod Mishra is a Fellow in Population and Health Studies at the East-West Center in Honolulu.

Xiaolei Dai is a Project Assistant in the Research Program at the East-West Center in Honolulu.

Kirk R. Smith is a Professor in the School of Public Health at the University of California at Berkeley and a Senior Fellow in the Research Program at the East-West Center in Honolulu.

Lasten Mika is the Energy Programmes Manager at the Intermediate Technology Development Group Southern Africa in Harare.

East-West Center Working Papers: Population and Health Series is an unreviewed and unedited prepublication series reporting on research in progress. The views expressed are those of the authors and not necessarily those of the Center. Please direct orders and requests to the East-West Center's Publication Sales Office. The price for Working Papers is $\$ 3.00$ each plus shipping/handling.

Address correspondence to: Dr. Vinod Mishra, Population and Health Studies, East-West Center, 1601 East-West Road, Honolulu, HI 96848-1601, USA; Tel: (1-808) 944-7452; Fax: (1-808) 944-7490; Email: MishraV@EastWestCenter.org. 


\title{
Maternal exposure to biomass smoke and reduced birth weight in Zimbabwe
}

\author{
ABSTRACT \\ Purpose. To examine the association between household use of biomass fuels for cooking \\ and birth weight. \\ Methods. Analysis is based on 3559 childbirths in the five years preceding the 1999 \\ Zimbabwe Demographic and Health Survey. Birth weights, recorded by trained \\ professionals at local health clinics, were derived from health cards at home or from \\ mother's recall. Multiple regression method was used to estimate the effect of household \\ use of biomass cooking fuels (wood, dung, or straw) on birth weight, after controlling for \\ child's sex and birth order, mother's education and nutritional status, pregnancy care, \\ household living standard, and other potentially confounding factors. \\ Results. Babies born to mothers cooking with wood, dung, or straw were $175 \mathrm{~g}$ lighter \\ (95\% CI: $-300,-50)$, on average, compared with babies born to mothers using LPG, \\ natural gas, or electricity. The difference was 120 g (95\% CI: -301, 61) for children \\ whose birth weights were taken from health cards, and $183 \mathrm{~g}(95 \% \mathrm{CI}:-376,10)$ for \\ children whose birth weights were reported by mothers. \\ Conclusions. Household use of high pollution cooking fuels may cause reduced birth \\ weight. The relationship needs to be further investigated using more direct measures of \\ smoke exposure and birth weight and accounting for environmental tobacco smoke.
}

Key words (MeSH headings): air pollution, indoor, smoke, biomass, pregnancy outcomes, birth weight, child, Zimbabwe 
Abbreviations: OR—Odds Ratio

$\mathrm{CO}$ - Carbon Monoxide

$\mathrm{PM}_{10}$-Particulate Matter with diameters less than 10 microns

SLI—Standard of Living Index

SES-Socioeconomic Status

LPG—Liquid Petroleum Gas

ETS-Environmental Tobacco Smoke

BMI—Body Mass Index

LBW—Low Birth Weight

ARI-Acute Respiratory Infection 


\section{INTRODUCTION}

A recent study based on 1,717 women and their newborn children in rural Guatemala reported an association between household use of wood fuels and reduced birth weight (1). The study found that babies born to mothers using wood fuels were 63 grams lighter, on average, than those born to mothers using gas or electricity, after adjustment for a number of socioeconomic and maternal factors. This study provided a first report of an association between biofuel use and reduced birth weight in a human population. To examine this relationship further, we designed a similar study based on data from a recent national household survey in Zimbabwe.

The 1999 Zimbabwe Demographic and Health Survey (ZDHS) collected information on birth weight for children born during the five years preceding the survey (2). Unlike most developing-country situations where a large majority of deliveries take place at home and only a small proportion of children are weighed at birth, in Zimbabwe three-quarters of children are born in a health facility and weighed at birth. The ZDHS, a nationally representative probability sample, also asked about household use of cooking fuels, which is the best single indicator of exposure to smoke indoors.

Smoke from biomass combustion produces a large number of health-damaging air pollutants including respirable particulate matter, carbon monoxide, nitrogen oxides, formaldehyde, benzene, 1,3 butadiene, polycyclic aromatic hydrocarbons (such as benzo[a]pyrene), and many other toxic organic compounds (3). In developing countries, where large proportions of households rely on biomass fuels for cooking and space 
heating, concentrations of these air pollutants tend to be highest indoors. The fuels are typically burned in simple, inefficient, and mostly unvented household cookstoves, which, combined with poor ventilation, generate large volumes of smoke indoors. In such settings, daily average and peak exposures to air pollutants often far exceed safe levels recommended by the World Health Organization $(3,4)$. Exposure levels are usually much higher among women who tend to do most of the cooking (5).

A recent baseline survey in two districts of Zimbabwe found that women, on average, spend five hours per day in the kitchen area. The measured levels of CO in the kitchen were in the range of 300-1000 ppm and levels of $\mathrm{PM}_{10}$ were in the range of 1000-4000 $\mu \mathrm{g} / \mathrm{m}^{3}(6)$.

Two previous studies in Zimbabwe have examined health effects of biomass smoke. One study compared 244 children under age 3 who visited a hospital with lower respiratory disease with 500 children of similar nutritional and socioeconomic background and found a significant association between the presence of woodsmoke pollution in the house and lower respiratory disease (7). A second study of 3559 children age 0-59 months, included in the 1999 ZDHS, reported that children in households using wood, dung, or straw for cooking were more than twice as likely to have suffered from ARI as children from households using LPG, natural gas, or electricity ( $\mathrm{OR}=2.20 ; 95 \% \mathrm{CI}: 1.16,4.19)$, after statistically controlling for several confounding factors (8). 
In other settings, biomass smoke exposure has been associated with a host of respiratory diseases (9), but little is known about its effects on pregnancy outcomes. Rural Guatemala study is the only study that seems to have reported an association between wood fuel use and reduced birth weight (1), although an Indian study reported significantly increased risk of stillbirths among women cooking with biomass fuels during pregnancy (10).

In addition to the large literature on active smoking, studies have linked exposure to passive tobacco smoke to fetal growth and adverse pregnancy outcomes, including low birth weight (11-16). Although there are differences, in nicotine content, for example, the incomplete combustion products thought to be responsible for most of the health effects in tobacco smoke are also found in smoke from other forms of biomass combustion, such as wood or dung. The concentrations found in typical household cooking situation, however, are often much higher than found in passive smoking studies, although much lower than active smoking (17).

Exposure to $\mathrm{CO}$ has been associated with fetal development and adverse pregnancy outcomes including reduced birth weight (18-20). Levels of CO in homes using biomass fuels are sometimes high enough to result in carboxyhemoglobin levels comparable to those in smokers $(5,21)$.

In recent years, an increasing number of studies have found an association between adverse pregnancy outcomes, including intrauterine growth retardation and reduced birth 
weight, and maternal exposure to outdoor air pollution at levels of pollution substantially lower than found in biomass-burning homes (22-27).

\section{MATERIAL AND METHODS}

The analysis is based on 3559 childbirths during the five years preceding the ZDHS. The survey collected demographic, socioeconomic, and health information from a nationally representative probability sample of 6,369 households, representing all 10 provinces. The sample is a two-stage cluster sample with an overall response rate of $97.8 \%$. In the first stage, 230 enumeration areas were selected with equal probability. In the second, households were selected using the probability proportional to size (PPS) sampling, after a complete household listing and mapping of the selected enumeration areas. To allow estimation of demographic and health parameters separately for the provinces, the sampling design allowed for over sampling of smaller strata. The survey questionnaires were translated into Shona and Ndebele languages, and back translated to ensure quality. The questionnaires were field-tested in April 1999 in 150 households in Bulawayo and Gweru areas. Training for the field staff for the main survey was conducted over a fourweek period in July 1999. Data were collected during 15 August to 30 November 1999. Further details about the sampling design, survey management, and quality control are provided in the basic survey report (2).

For each childbirth during the five years preceding the survey, the mother was asked if the child was weighed at the time of birth. For those weighed at birth, the mother was asked to show the health card and the birth weight was recorded (in grams) from the card. 
For mothers who did not have the card, birth weight was recorded based on mother's recall. About three-fourths of childbirths in Zimbabwe take place in health facilities and for most of these children trained health professionals record birth weights (2). This reported birth weight (from health card or mother's recall) is the response variable in our analysis. Multiple births ( $3 \%$ of the sample) and births with missing information on birth weight (3\%) were excluded from the analysis.

Birth weights were recorded to the nearest $10 \mathrm{~g}$, but in the ZDHS data, even for children whose birth weights were taken from health cards, there is considerable heaping around birth weights ending in $100 \mathrm{~g}$, indicating that many health workers recorded birth weights to the nearest $100 \mathrm{~g}$. As expected, such heaping is somewhat more common in the case of mother's recall. ZDHS data do not allow an assessment of the magnitude or direction of the effect of this heaping on our results.

The survey used an eight-fold classification of main cooking fuel—wood, dung, straw, charcoal, kerosene, electricity, liquid petroleum gas (LPG)/natural gas, and a residual category of other fuels. The question was, "What type of fuel does your household mainly use for cooking?" Information on fuel types was used to group households into three categories representing the extent of exposure to cooking smoke- - high pollution fuels (wood, dung, or straw), medium pollution fuels (kerosene or charcoal), and low pollution fuels (LPG/natural gas or electricity). Households using the medium pollution fuels and the residual category of other fuels (11\%) were excluded from the analysis. 
A number of multivariate regression models were estimated using the SURVEYREG procedure in the SAS System (28). Control variables included sex of child, birth order of child, mother's age at childbirth, mother's body mass index (BMI), mother received iron supplement during pregnancy, mother received drug for malaria during pregnancy, mother's education in completed years, mother's religion, household standard of living, and region of residence. Urban/rural residence was originally considered a possible covariate of birth weight, but it was dropped owing to its collinearity with cooking fuel type (see below). Because most women in Zimbabwe (98\%) received antenatal care visits, we were unable to include this variable in the analysis. Moreover, because information on pregnancy care (iron supplements and malaria drugs during pregnancy) was collected only for the last birth in the 5-year period, multivariate analysis of effects of cooking fuel on birth weight was limited only to the last births.

A weighting factor was applied to all observations to compensate for over-sampling of certain categories of respondents in the study design. Results are presented as mean birth weight estimates with significance levels for categories of each predictor variable by holding other variables in the model constant at their mean values (29). For the effects of cooking fuel, $95 \%$ confidence intervals are also presented in the text. Estimation of standard errors takes into account design effects due to clustering at the level of the primary sampling unit. 


\section{RESULTS}

Table 1 shows the sample distribution of births in the five years preceding the survey by whether they were weighed at birth, cooking fuel, and other variables. Seventy-eight percent of all children born during the five years preceding the survey were weighed at birth. Children who were not weighed at birth are considerably more likely to be from biomass-fuel-using households compared to those who were weighed at birth $(91 \%$ compared to $59 \%$, respectively). This differential in the likelihood of being weighed at birth by cooking fuel type has implications for the results of this study (see below). Children who were weighed are more likely to be first order births, births to younger mothers, births to mothers who received iron supplementation during pregnancy, and births to Christian mothers than other births. As expected, children who were not weighed at birth are disproportionately from poorer households. The likelihood of being weighed at birth also varies considerably by region of residence.

$<$ Table 1 about here $>$

Health cards were available for $53 \%$ of the children who were weighed at birth. For the remaining $47 \%$, the mother reported the birth weight. Children in poorer households and in households using high pollution fuels were slightly more likely to have health cards available at the time of the survey, compared with children in richer households and in households using cleaner fuels. The sample distributions of children by source of information on birth weight were quite similar by other background characteristics.

Among children who were weighed at birth, few (8\%) are of low birth weight (LBW) of under $2500 \mathrm{~g}$ (Table 2). Children in biomass fuel using households were slightly more 
likely to be low birth weight $(8.6 \%)$ than those in electricity, natural gas, or LPG using households $(7.7 \%)$, but the difference was not significant statistically. The mean birth weight of children born in the past five years who were weighed at birth is $3140 \mathrm{~g}(95 \%$ CI: 3119, 3161). A comparison of birth weight distribution from health card and from mother's recall shows that children whose birth weights were based on mother's recall (3174 g) tend to be heavier than those whose birth weights were from health card (3111 g). This is consistent with the evidence in Table 1 that children in higher socioeconomic status (SES) households were less likely to have health cards.

\section{$<$ Table 2 about here $>$}

The average height of Zimbabwe women is $159 \mathrm{~cm}$, and less than $2 \%$ of women are shorter than $145 \mathrm{~cm}$. Similarly, only $4 \%$ of the mothers recorded a body mass index (BMI) below $18.5 \mathrm{~kg} / \mathrm{m}^{2}$ (2). According to the WHO guidelines, adult women of height shorter than $145 \mathrm{~cm}$ and BMI below $18.5 \mathrm{~kg} / \mathrm{m}^{2}$ are considered undernourished and at a greater risk of giving birth to low birth weight babies (30).

Table 3 shows the observed mean birth weight by type of cooking fuel and estimated mean birth weight by fuel type and other variables from alternative multiple regression models. The table shows that children born to mothers cooking with high pollution biomass fuels were $50 \mathrm{~g}$ lighter, on average, than children born to mothers using LPG, natural gas, or electricity.

\section{$<$ Table 3 about here $>$}

The effect of cooking fuel on birth weight becomes considerably greater when child's sex and birth order are controlled statistically in Model 1. With child's sex and birth order 
controlled, children born to mothers cooking with biomass fuels are $75 \mathrm{~g}$ lighter at birth $(p<0.01)$. Interestingly, girls tend to be much lighter than boys at birth $(123 \mathrm{~g})$. The mean birth weight increases significantly with birth order, with first order births having a lower mean birth weight. This positive relationship between birth order and birth weight is responsible for an increase in the effect of cooking fuel. High pollution fuel is positively related with higher birth order (fertility tends to be higher among mothers cooking with high pollution fuels due to their lower socioeconomic status), but negatively related with birth weight, so when the effect of birth order is controlled it sharpens the effect of cooking fuel type.

Even when mother's characteristics — age at childbirth, BMI, iron supplement, malaria drug, education, religion — and household living standard are additionally controlled in Model 2, the effect of cooking with biomass fuels on birth weight remains large and significant (114 g; 95\% CI: -224, -4). If anything, controlling for the six maternal characteristics and household living standard further sharpens the effect of cooking fuel type. As expected, mother's BMI has a large positive effect on birth weight ( $p=.0031)$. Also, as expected, mother's receiving iron tablets during pregnancy has a large positive effect on birth weight $(p=.0008)$. But the effects of mother's age at childbirth, receiving malaria drugs during pregnancy, education, religion, and household living standard are small and not significant statistically.

In the full model (Model 3), when all child characteristics, maternal characteristics, household living standard, as well as region of residence are controlled, the effect of 
cooking with biofuels is further sharpened. With other variables in the model controlled statistically by holding constant at their mean values, children born to mothers cooking with high pollution biomass fuels are $175 \mathrm{~g}$ lighter $(95 \% \mathrm{CI}:-300,-50)$, on average, than those born to mothers cooking with LPG, natural gas, or electricity $(p=0.006)$. Additionally controlling for region of residence in Model 3 makes virtually no difference to the effects of other variables. In Model 3, the effects of child's sex, birth order, mother's BMI, and mother's receiving iron tablets during pregnancy remain large and significant, but none of the other variables, including mother's age at childbirth, receiving malaria drugs during pregnancy, mother's education, and household living standard, has any statistically significant effect.

Table 4 repeats the full model in Table 3 (Model 3) separately by source of information on birth weight. With other variables controlled, children in households using high pollution biomass fuels are lighter than those in households using electricity or gaseous fuels in both groups $-120 \mathrm{~g}$ lighter in the group where birth weight was recorded from a health card (95\% CI: -301, 61), and $183 \mathrm{~g}$ lighter in the group where mother reported the birth weight from recall $(95 \%$ CI: $-376,10)$. These effects of cooking fuel type on birth weight are not statistically significant at the $5 \%$ level due to small numbers of cases. Among the control variables, only two variables — sex of child, and mother's receiving iron tablets during pregnancy—have statistically significant effects on birth weight in both groups. Child's birth order and mother's BMI have significant effects in the group where birth weights were recorded from health card, but not in the group where birth weights were based on mother's recall. 
$<$ Table 4 about here $>$

\section{DISCUSSION}

Results suggest that exposure to cooking smoke from biomass combustion is associated with reduced birth weight, independent of child's sex, birth order, mother's nutritional status, pregnancy care, mother's education, household living standard, and other factors. These results are consistent with the earlier Guatemalan study linking wood fuels to reduced birth weight (1), and provide further evidence that cooking with high pollution unprocessed biomass fuels can increase the risk of adverse pregnancy outcomes.

The ZDHS data provide an unique opportunity to study the relationship between biomass fuel use and birth weight because birth weight data are rare in developing countries where a great majority of births occur at home. Moreover, data on birth weight and cooking fuels are rarely available from the same source to allow such analyses. Nevertheless, several measurement constraints should be kept in mind when considering the findings of this study.

First, because the survey did not collect information on tobacco smoking by household members, we were unable to control for environmental tobacco smoke (ETS), which is a known risk factor for adverse pregnancy outcomes including low birth weight. Maternal smoking is not a significant confounding factor because few women smoke $(1.47 \%$ in the 1999 ZDHS sample). 
Second, we were unable to control directly for urban/rural residence owing to its collinearity with cooking fuel type $(r=0.95)$. This may have biased our estimated effects to some degree. However, our analysis includes controls for measures of mother's nutritional status (BMI), pregnancy care, and SES, such as mother's education and household living standard, which may provide some gradient of exposure within urban and rural populations. Also, the analysis controls for residence in the provinces of Zimbabwe, including two exclusively urban provinces of Harare and Bulawayo. We feel that controlling for mother's nutritional status, pregnancy care, SES, and region adequately controls for potential confounding effects of urban/rural residence. Moreover, other similar studies of national survey data have found no statistically significant effects of urban/rural residence after controlling for SES, and in these studies controlling for urban/rural residence did not alter the effects of cooking fuel $(31,32)$.

Third, as mentioned above, there is bias in the sample because children who were not weighed at birth were disproportionately from biofuel-using homes. If all children were weighed at birth, our estimates of effect of biofuel would be even greater. The correlation between likelihood of being weighed and birth order, maternal age, religion, and household living standard, as well as relying on mother's recall for $47 \%$ of the birth weights may also have biased our results to some degree, but the direction is unclear.

Fourth, many households in Zimbabwe use a combination of fuels, whereas we have information only on the primary cooking fuel. Our estimated effects would be larger if we could compare birth weights in households using only biomass fuels with those using 
only LPG, natural gas, or electricity. Fifth, there is a possibility that some mothers might have shifted from biomass fuels to cleaner fuels during the last five years, the period for which birth weight is recorded. Our estimated effects are also underestimated to the extent this occurs.

Children with lower birth weight are more likely to die than children with higher birth weight, but since the survey includes birth weight information on all live births, selective mortality due to lower birth weight is not a problem. However, there might be bias due to higher rates of miscarriage and stillbirth among mothers cooking with high pollution biomass fuels than among mothers cooking with low pollution fuels (9). To the extent these pregnancies, if carried to term, would have been lower birth weight among mothers cooking with biomass fuels, this effect contributes to underestimation of the effect.

As mentioned earlier, information on smoke exposure was ascertained from type of fuel used for cooking, the best single question for determining indoor smoke exposures. Nevertheless, our research needs to be followed by carefully designed studies with better measures of smoke exposure and clinical measures of pregnancy outcomes including birth weight. Such research is important in view that a large proportion of households in Zimbabwe and other developing countries rely on biomass fuels for household energy and low birth weight is a known risk factor for childhood ill health and death. 


\section{ACKNOWLEDGEMENTS}

Authors are thankful to Nigel Bruce, Eva Rehfuess, and three anonymous reviewers for useful comments on an earlier draft. The study was supported in part by a grant from the National Institute of Child Health and Human Development (\#1 R03 HD043929-01). An

earlier version of this paper was presented at the $131^{\text {st }}$ American Public Health Association Annual Meeting in San Francisco, November 15-19, 2003. 


\section{REFERENCES}

1. Boy E, Bruce N, Delgado H. Birth weight and exposure to kitchen wood smoke during pregnancy in rural Guatemala. Environ Health Perspect 2002;110:109-114.

2. Central Statistical Office Zimbabwe and Macro International Inc. Zimbabwe Demographic and Health Survey, 1999. Calverton, Maryland: Central Statistical Office and Macro International Inc. 2000.

3. Bruce N, Perez-Padilla R, Albalak R. Indoor air pollution in developing countries: a major environmental and public health challenge. Bull World Health Organ 2000;78:1080-1092.

4. World Health Organization (WHO). Health and Environment for Sustainable Development: Five Years After the Earth Summit. Geneva: World Health Organization. 1997.

5. Behera D, Dash S, Malik SK. Blood carboxyhaemoglobin levels following acute exposure to smoke of biomass fuel. Indian J Med Res 1988;88:522-524.

6. Mika L. Addressing health and household energy problem in Zimbabwe. Proceedings of the $9^{\text {th }}$ International Conference on Indoor Air Quality and Climate; 2002 June 30July 05; Monterey CA. 2002.

7. Collings DA, Sithole SD, Martin KS. Indoor woodsmoke pollution causing lower respiratory disease in children. Trop Doct 1990;20:151-155.

8. Mishra V. Indoor air pollution from biomass combustion and acute respiratory illness in preschool age children in Zimbabwe. Int J Epidemiol 2003;32:847-853. 
9. Smith KR, Mehta S, Feuz M. In press. Indoor air pollution from household use of solid fuels. In: Comparative Quantification of Health Risks: Global and Regional Burden of Disease due to Selected Major Risk Factors. (eds). M. Ezzati, A. Rodgers D, Lopez AD, Murray CJL. Geneva: World Health Organization. 2003.

10. Mavalankar DV, Trivedi CR, Gray RH. Levels and risk factors for perinatal mortality in Ahmedabad, India. Bull World Health Organ 1991;69:435-642.

11. Dejmek J, Selevan SG, Benes I, Solansky I, Sram RJ. Fetal growth and maternal exposure to particulate matter during pregnancy. Environ Health Perspect $1999 ; 107: 475-480$.

12. Martin TR, Bracken MB. 1986. Association of low birth weight with passive smoke exposure in pregnancy. Am J Epidemiol 2002;124:633-642.

13. Mathai M, Vijayasri R, Babu S, Jeyaseelan L. Passive maternal smoking and birthweight in a south Indian population. Br J Obstet Gynaecol 1992;99:342-343.

14. Rubin DH, Krasilnikoff PA, Leventhal JM, Weile B, Berget A. Effect of passive smoking on birth-weight. Lancet 1986;2(8504):415-417.

15. Windham GC, Eaton A, Hopkins B. Evidence for an association between environmental tobacco smoke exposure and birthweight: a meta-analysis and new data. Paediatr Perinat Epidemiol 1999;13:35-57.

16. Windham GC, Hopkins B, Fenster L, Swan SH. Prenatal active or passive tobacco smoke exposure and the risk of preterm delivery or low birth weight. Epidemiol $2000 ; 11: 427-433$.

17. Smith KR. Biofuel. Combustion and Health. New York, Plenum. 1987. 
18. Astrup P, Olsen HM, Trolle D, Kjeldsen K. Effect of moderate carbon-monoxide exposure on fetal development. Lancet 1972;2 (7789):1220-1222.

19. Longo LD. The biological effects of carbon monoxide on the pregnant woman, fetus, and newborn infant. Am J Obstet Gynecol 1977;129:69-103.

20. Garvey DJ, Longo LD. Chronic low level maternal carbon monoxide exposure and fetal growth and development. Biol Reprod 1978;19:8-14.

21. Dary O, Pineda O, Belizan JM. Carbon monoxide contamination in dwellings in poor rural areas of Guatemala. Bull Environ Contam Toxicol 1981;26:24-30.

22. Bobak M, Leon DA. Pregnancy outcomes and outdoor air pollution: an ecological study in districts of the Czech Republic 1986-8. Occup Environ Med 1999;56:539543.

23. Ritz B, Yu F. The effect of ambient carbon monoxide on low birth weight among children born in southern California between 1989 and 1993. Environ Health Perspect 1999;107:17-25.

24. Chen L, Yang W, Jennison BL, Goodrich A, Omaye ST. Air pollution and birth weight in northern Nevada, 1991-1999. Inhal Toxicol 2002;14:141-157.

25. Maisonet M, Bush TJ, Correa A, Jaakkola JJ. Relation between ambient air pollution and low birth weight in the Northeastern United States. Environ Health Perspect 2001;109(Suppl 3):351-356.

26. Ha EH, Hong YC, Lee BE, Woo BH, Schwartz J, Christiani DC. Is air pollution a risk factor for low birth weight in Seoul? Epidemiol 2001;12:643-648. 
27. Xu X, Ding H, and Wang X. Acute effects of total suspended particles and sulfur dioxides on preterm delivery: a community-based cohort study. Arch Environ Health 1995;50:407-415.

28. SAS Institute, Inc. SAS System for Windows, Release 8.02. Cary NC: SAS Institute, Inc. 2001.

29. Retherford RD, Choe MK. Statistical Models for Causal Analysis. New York: John Wiley \& Sons, Inc. 1993.

30. World Health Organization (WHO). Diet, nutrition and the prevention of chronic diseases. World Health Organ Tech Rep Ser. 2003;916:1-149.

31. Mishra V. Effect of indoor air pollution from biomass combustion on prevalence of asthma in the elderly. Environ Health Perspect 2003;111:71-77.

32. Mishra V, Retherford RD, Smith KR. Biomass cooking fuels and prevalence of tuberculosis in India. Int J Infect Dis 1999;3:119-129. 
Table 1 Sample distribution of births in the last five years for selected variables used in the analysis by whether weighed at birth or not, by source of information on birth weight, Zimbabwe, 1999

\begin{tabular}{|c|c|c|c|c|c|}
\hline \multirow[b]{2}{*}{ Variable } & \multicolumn{3}{|c|}{ Weighed at birth } & \multirow{2}{*}{$\begin{array}{r}\text { Not weighed } \\
\text { at birth }\end{array}$} & \multirow{2}{*}{$\begin{array}{r}\mathrm{Al} \\
\text { children }\end{array}$} \\
\hline & Card & Recall & Total & & \\
\hline \multicolumn{6}{|l|}{ Cooking fuel type $^{1}$} \\
\hline Medium pollution fuel & 8.9 & 15.3 & 11.9 & 5.7 & 10.5 \\
\hline Low pollution fuel & 26.0 & 33.0 & 29.3 & 3.5 & 23.7 \\
\hline \multicolumn{6}{|l|}{ Sex of child } \\
\hline Girl & 48.5 & 48.9 & 48.7 & 48.3 & 48.6 \\
\hline \multicolumn{6}{|l|}{ Birth order of child } \\
\hline 1 & 36.6 & 39.4 & 37.9 & 18.7 & 33.7 \\
\hline 2 & 23.6 & 24.4 & 24.0 & 18.9 & 22.9 \\
\hline 3 & 14.7 & 13.6 & 14.2 & 15.6 & 14.5 \\
\hline $4+$ & 25.2 & 22.7 & 24.0 & 46.8 & 28.9 \\
\hline \multicolumn{6}{|l|}{ Body mass index (BMI) } \\
\hline$<18.5$ & 4.3 & 3.9 & 4.1 & 5.1 & 4.3 \\
\hline $18.5-25.0$ & 69.2 & 65.9 & 67.6 & 75.7 & 69.3 \\
\hline$\geq 25.0$ & 26.6 & 30.3 & 28.3 & 19.2 & 26.4 \\
\hline \multicolumn{6}{|c|}{ Iron supplement during pregnancy } \\
\hline Yes & 63.8 & 61.6 & 62.8 & 51.7 & 60.6 \\
\hline No & 36.2 & 38.4 & 37.2 & 48.3 & 39.4 \\
\hline \multicolumn{6}{|c|}{ Malaria drug during pregnancy ${ }^{2}$} \\
\hline Yes & 23.2 & 22.1 & 22.7 & 23.6 & 22.9 \\
\hline No & 76.8 & 77.9 & 77.3 & 76.4 & 77.1 \\
\hline \multicolumn{6}{|c|}{ Education of mother (in year) } \\
\hline Low & 31.5 & 23.7 & 27.9 & 52.3 & 33.2 \\
\hline Medium & 36.8 & 39.0 & 37.8 & 40.5 & 38.4 \\
\hline High & 31.7 & 37.3 & 34.3 & 7.1 & 28.4 \\
\hline \multicolumn{6}{|l|}{ Region } \\
\hline Manicaland & 10.7 & 11.5 & 11.0 & 35.7 & 16.4 \\
\hline Mashonaland Central & 10.7 & 7.1 & 9.0 & 11.3 & 9.5 \\
\hline Mashonaland East & 8.6 & 9.9 & 9.2 & 7.7 & 8.9 \\
\hline Mashonaland West & 9.0 & 10.0 & 9.4 & 10.5 & 9.6 \\
\hline Matabeleland North & 6.5 & 1.9 & 4.3 & 7.7 & 5.1 \\
\hline Matabeleland South & 8.7 & 4.1 & 6.6 & 4.3 & 6.1 \\
\hline Midlands & 13.9 & 10.7 & 12.4 & 13.8 & 12.7 \\
\hline Masvingo & 10.9 & 12.3 & 11.5 & 5.6 & 10.3 \\
\hline Harare & 11.6 & 28.1 & 19.3 & 2.1 & 15.6 \\
\hline Bulawayo & 9.6 & 4.5 & 7.2 & 1.3 & 5.9 \\
\hline Number of births ${ }^{4}$ & 1,390 & 1,220 & 2,610 & 721 & 3,331 \\
\hline
\end{tabular}

Note: 108 multiple births and 120 births with missing information on birth weight are excluded from the analysis.

${ }^{1}$ High pollution fuels include firewood, straw, or dung; medium pollution fuels include kerosene or charcoal; low pollution fuels include electricity or LPG/natural gas.

${ }^{2}$ Available only for the last birth in the five years preceding the survey for each women. 
${ }^{3}$ Standard of living is measured by an index calculated by adding the following scores: 3 for a car or tractor; 2 each for a scooter/motorcycle, $\mathrm{TV}$, telephone, refrigerator, piped/public tap water, flush toilet, electricity, wood/vinyl/asphalt/ceramic/cement/carpet of main floor material; 1 each for a bicycle, radio. Index scores range from 0-2 for low SLI, 3-8 for medium SLI, 9-21 for high SLI.

${ }^{4}$ Number of births varies slightly depending on the number of missing cases at each variable. 
Table 2 Sample distribution of births in the five years preceding ZDHS by birth weight (grams), source of information on birth weight, and cooking fuel type, Zimbabwe 1999

\begin{tabular}{|c|c|c|c|c|c|}
\hline \multirow[b]{2}{*}{ Birth weight (grams) } & \multicolumn{2}{|c|}{ Source of information on birth weight } & \multicolumn{2}{|c|}{ Cooking fuel type } & \multirow[b]{2}{*}{ All children } \\
\hline & Card & Recall & High pollution & Low pollution & \\
\hline$<2500$ & 6.86 & 10.30 & 8.58 & 7.70 & 8.46 \\
\hline $2500-2999$ & 30.31 & 23.72 & 28.06 & 24.63 & 27.23 \\
\hline $3000-3499$ & 41.01 & 29.99 & 35.28 & 36.71 & 35.86 \\
\hline 3500-3999 & 17.32 & 25.10 & 19.53 & 24.67 & 21.00 \\
\hline $4000+$ & 4.50 & 10.80 & 8.55 & 6.29 & 7.45 \\
\hline Total births & 1,390 & 1,220 & 1,535 & 764 & 2,610 \\
\hline Mean birth weight & 3,111 & 3,174 & 3,132 & 3,175 & 3,140 \\
\hline $95 \% \mathrm{Cl}$ & $(3087,3135)$ & $(3136,3212)$ & $(3104,3160)$ & $(3128,3221)$ & $(3119,3162)$ \\
\hline
\end{tabular}


Table 3 Observed and predicted mean birth weight (grams) of children born during the five years preceding the ZDHS ${ }^{1}$ by type of cooking fuel and other selected variables, Zimbabwe, 1999 (all birth weights from card and recall)

\begin{tabular}{|c|c|c|c|c|}
\hline \multirow[b]{3}{*}{ Variable } & \multicolumn{4}{|c|}{ Mean birth weight (grams) } \\
\hline & \multirow{2}{*}{ Observed } & \multicolumn{3}{|c|}{$\begin{array}{r}\text { Predicted } \\
\end{array}$} \\
\hline & & Model 1 & Model 2 & Model 3 \\
\hline \multicolumn{5}{|l|}{ Cooking fuel type } \\
\hline High pollution fuel & 3,137 & $3,129 * *$ & 3,117 * & $3,096 * *$ \\
\hline Low pollution fuel^ & 3,187 & 3,204 & 3,232 & 3,271 \\
\hline \multicolumn{5}{|l|}{ Sex of child } \\
\hline Boy^ & & 3,214 & 3,222 & 3,222 \\
\hline Girl & & $3,091 * * *$ & $3,088^{* * *}$ & $3,088 * * *$ \\
\hline \multicolumn{5}{|l|}{ Birth order of child } \\
\hline $1^{\wedge}$ & & 3,039 & 3,075 & 3,078 \\
\hline 2 & & $3,174^{* * *}$ & $3,197^{* * *}$ & $3,196 * *$ \\
\hline 3 & & $3,202 * * *$ & 3,179 * & 3,177 \\
\hline $4+$ & & $3,261 * * *$ & 3,214 * & $3,211 *$ \\
\hline \multicolumn{5}{|l|}{ Mother's age at child birth } \\
\hline $15-24^{\wedge}$ & & & 3,131 & 3,130 \\
\hline $25-34$ & & & 3,165 & 3,165 \\
\hline $35-49$ & & & 3,249 & 3,254 \\
\hline \multicolumn{5}{|l|}{ Body mass index (BMI) } \\
\hline 18 & & & $3,084 * *$ & $3,083 * *$ \\
\hline 23 & & & $3,147^{* *}$ & $3,147^{* *}$ \\
\hline 28 & & & $3,210 * *$ & $3,210 * *$ \\
\hline \multicolumn{5}{|c|}{ Iron supplement during pregnancy } \\
\hline Yes & & & $3,189 * * *$ & $3,191 * * *$ \\
\hline $\mathrm{No}^{\wedge}$ & & & 3,103 & 3,100 \\
\hline \multicolumn{5}{|c|}{ Malaria drug during pregnancy } \\
\hline Yes & & & 3,188 & 3,175 \\
\hline $\mathrm{No}^{\wedge}$ & & & 3,147 & 3,151 \\
\hline \multicolumn{5}{|c|}{ Education of mother (in year) } \\
\hline $0-3^{\wedge}$ & & & 3,149 & 3,150 \\
\hline $3-6$ & & & 3,145 & 3,145 \\
\hline $6+$ & & & 3,182 & 3,182 \\
\hline \multicolumn{5}{|l|}{ Religion of mother } \\
\hline Christian^ & & & 3,167 & 3,167 \\
\hline Non-Christian & & & 3,102 & 3,102 \\
\hline \multicolumn{5}{|l|}{ Standard of living index } \\
\hline Low^ $^{\wedge}$ & & & 3,172 & 3,168 \\
\hline Medium & & & 3,190 & 3,189 \\
\hline High & & & 3,110 & 3,115 \\
\hline \multicolumn{5}{|l|}{ Region } \\
\hline Manicaland & & & & 3,180 \\
\hline Mashonaland Central & & & & 3,123 \\
\hline Mashonaland East & & & & 3,219 \\
\hline Mashonaland West & & & & 3,122 \\
\hline Matabeleland North & & & & 3,156 \\
\hline Matabeleland South & & & & 3,181 \\
\hline Midlands & & & & 3,239 * \\
\hline Masvingo & & & & 3,191 \\
\hline Harare $^{\wedge}$ & & & & 3,106 \\
\hline Bulawayo & & & & 3,028 \\
\hline Number of births & 1,939 & 1,939 & 1,734 & 1,734 \\
\hline
\end{tabular}

\footnotetext{
${ }^{1}$ Analysis in this table is limited to last births only.

${ }^{\wedge}$ Reference category

${ }^{*} p<.05,{ }^{* *} p<.01,{ }^{* * *} p<.001$
} 
Table 4 Predicted mean birth weight (grams) of children born during the five years preceding the ZDHS ${ }^{1}$ by type of cooking fuel and other selected variables, separately by source of information on birth weight, Zimbabwe 1999

\begin{tabular}{|c|c|c|}
\hline \multirow[b]{2}{*}{ Variable } & \multicolumn{2}{|c|}{ Mean birth weight (grams) } \\
\hline & Card & Recall \\
\hline \multicolumn{3}{|l|}{ Cooking fuel type } \\
\hline High pollution fuel & 3,085 & 3,131 \\
\hline Low pollution fuel^ & 3,205 & 3,314 \\
\hline \multicolumn{3}{|l|}{ Sex of child } \\
\hline Boy^ & 3,178 & 3,284 \\
\hline Girl & $3,060 * * *$ & $3,122 * * *$ \\
\hline \multicolumn{3}{|l|}{ Birth order of child } \\
\hline $1^{\wedge}$ & 3,012 & 3,165 \\
\hline 2 & $3,139 * *$ & 3,281 \\
\hline 3 & $3,149 *$ & 3,233 \\
\hline $4+$ & $3,219 * *$ & 3,177 \\
\hline \multicolumn{3}{|l|}{ Mother's age at child birth } \\
\hline $15-24^{\wedge}$ & 3,109 & 3,153 \\
\hline $25-34$ & 3,105 & 3,256 \\
\hline $35-49$ & 3,208 & 3,331 \\
\hline \multicolumn{3}{|l|}{ Body mass index (BMI) } \\
\hline 18 & $3,052 * *$ & 3,129 \\
\hline 23 & 3,112 ** & 3,194 \\
\hline 28 & $3,173 * *$ & 3,259 \\
\hline \multicolumn{3}{|c|}{ Iron supplement during pregnancy } \\
\hline Yes & 3,148 * & 3,252 * \\
\hline $\mathrm{No}^{\wedge}$ & 3,072 & 3,133 \\
\hline \multicolumn{3}{|c|}{ Malaria drug during pregnancy } \\
\hline Yes & 3,110 & 3,271 \\
\hline $\mathrm{No}^{\wedge}$ & 3,123 & 3,187 \\
\hline \multicolumn{3}{|c|}{ Education of mother (in year) } \\
\hline $0-3^{\wedge}$ & 3,088 & 3,222 \\
\hline $3-6$ & 3,123 & 3,181 \\
\hline $6+$ & 3,141 & 3,235 \\
\hline \multicolumn{3}{|l|}{ Religion of mother } \\
\hline Christian^^ & 3,130 & 3,218 \\
\hline Non-Christian & 3,076 & 3,127 \\
\hline \multicolumn{3}{|l|}{ Standard of living index2 } \\
\hline Low $^{\wedge}$ & 3,129 & 3,215 \\
\hline Medium & 3,131 & 3,258 \\
\hline High & 3,099 & 3,156 \\
\hline \multicolumn{3}{|l|}{ Region } \\
\hline Manicaland & 3,187 & 3,147 \\
\hline Mashonaland Central & 3,074 & 3,200 \\
\hline Mashonaland East & 3,209 & 3,232 \\
\hline Mashonaland West & 3,045 & 3,235 \\
\hline Matabeleland North & 3,162 & 3,047 \\
\hline Matabeleland South & 3,152 & 3,210 \\
\hline Midlands & 3,159 & $3,387 * *$ \\
\hline Masvingo & 3,142 & 3,245 \\
\hline Harare $^{\wedge}$ & 3,037 & 3,152 \\
\hline Bulawayo & 3,032 & 3,048 \\
\hline Number of births & 996 & 738 \\
\hline
\end{tabular}

\footnotetext{
${ }^{1}$ Analysis in this table is limited to last births only.

^Reference category

${ }^{*} p<.05,{ }^{* *} p<.01,{ }^{* * *} p<.001$
} 